\title{
Increasing the reliability and manoeuvrability of the CCGT when operating in the variable part of the power consumption schedules by switching the CCGT steam turbine to the motor mode
}

\author{
Edik Arakelyan ${ }^{1, *}$, Alexander Andryushin ${ }^{1}$, Fedor Pashchenko ${ }^{2}$, Sergey Mezin ${ }^{1}$, Konstantin Andryushin ${ }^{1}$ and \\ Anatoly Kosoy ${ }^{1}$ \\ ${ }^{1}$ National Research University “MPEI”, ACS HP Department, 111250 Moscow, Russia \\ ${ }^{2}$ V. A. Trapeznikov Institute of Control Sciences of Russian Academy of Sciences, 117997 Moscow, Russia
}

\begin{abstract}
The report is devoted to the problem of increasing the reliability and manoeuvrability of the CCGT when it operates in power control modes of the power system. The generalized results of research on improving the reliability and expanding the adjustment range of the PGU-450 based on the use of bypass steam distribution, reducing the duration of start-up operations and increasing the loading speed of the steam turbine and CCGT in general in the modes of CCGT power reserve during the night load gap by transferring the CCGT steam turbine to the motor mode when the CCGT operates in the condensation mode or in the heating mode according to the GTU-CHP scheme are presented. Additional advantages of the motor mode are noted: improved reliability of the steam turbine due to the elimination of cyclic temperature fluctuations of its steam inlet valves and vibrations in the last stages of the low-pressure cylinder and the possibility of operating the steam turbine generator in the synchronous compensator mode.
\end{abstract}

\section{Introduction}

In the Russian power industry, the established tradition of designing highly efficient but low-manoeuvrable power units on organic fuel has led to the fact that at all times, including at the present time, the manoeuvrable characteristics of the existing main equipment of thermal power plants do not correspond to the variable nature of the schedules of electric loads of power systems, which creates difficulties in covering the variable part and especially in passing the gaps of the schedules of energy consumption. It would seem that the preferential commissioning of combined-cycle gas plants (CCGTs) in recent years can save the situation, given the presence of highly manoeuvrable gas turbines in them. However, the well-known fact that an increase in the operating time of CCGTs at low and variable loads is associated with a significant decrease in the economic efficiency and reliability of their operation (especially gas turbines), leads to a cautious approach to involving CCGTs in regulating the load and frequency of the power system. We should not forget that the design resource characteristics of gas turbines are significantly less than those of steam turbines. Therefore, gas turbine manufacturers limit the total number of shutdowns in the reserve. However, at present, participation of power plants in system services is mandatory for all types of power plants, including CCGTs. This participation leads to the fact that the operation of generating equipment in the variable part of the load schedules is profitable for power plants, since system services are funded additionally, but provided that the corresponding requirements for manoeuvrability and reliability are met. This also serves as a motivation for power plants to find ways to improve the manoeuvrability of equipment, including CCGT.

As you know, the concept of "manoeuvrability" is a set of technical indicators, the totality of which shows the ability of the equipment to meet all the requirements of a variable electrical load schedule. It includes the following features: adjustment range; mobility - the rate of load change per minute (absolute or as a percentage of rated power); starting characteristics of the power unit the duration of starts after downtime in the reserve of various durations; the probability of successful start-up in accordance with the standard start-up schedules; starting fuel losses. For reliable and economical operation of power systems while reducing electrical consumption during night hours and non-working days, power units must have favourable starting characteristics that meet the technical requirements for manoeuvrability dictated by power systems. Reducing the duration of preparatory start-up operations is also an important factor along with the speed or duration of loading. With a long duration of start-up operations, start-up losses

*Corresponding author: Edik_Arakelyan@inbox.ru 
increase unreasonably, and the organization of work of operating personnel becomes difficult.

Thus, it becomes obvious that, while maintaining the tendency to increase the share of high-efficiency CCGT in total capacity of the power system, designed to work with basic graphs of the electric loading without due regard for the requirements of user's manoeuvrability combined-cycle units, in conditions of almost complete lack of input into the power system highly manoeuvrable power plants will lead to the fact that the problems of manoeuvrability for power systems and power plants will be highly topical and will require greater effort to overcome them. All this shows the urgent need and timeliness of research aimed at developing technical solutions aimed at improving the manoeuvrability characteristics of CCGT equipment, especially in terms of expanding the adjustment range and reducing the duration and increasing the reliability of stop-start modes.

As a rule, when operating a CCGT in condensation mode, if it is necessary to involve it in regulating load schedules or for passing night load gaps, the presence of restrictions on the adjustment range leads to the need to stop one gas turbine and transfer the CCGT to the operation mode with incomplete equipment. Consequences - reduced resource characteristics of a stopped gas turbine, fuel loss during reverse start-up, etc. Another problem with CCGT manoeuvrability is the significant difference in manoeuvrability indicators in terms of the duration of start-up operations of gas and steam turbines in start-up modes from different thermal states. So, after stopping for 8-10 hours, the gas turbine is started and loaded to the rated load in 15-20 minutes, while it takes 65-70 minutes to start and load the steam turbine $[1,2]$. The main reason for increasing the startup time of a steam turbine is the appearance of a temperature difference in the width of the flanges, between the flange and the pin, and the appearance of a large relative elongation of the rotors when it is loaded. This is a consequence of uneven heating of individual turbine units, especially the thick-walled housing of the high pressure cylinder (HPC). This leads to the fact that when the CCGT is stopped for the purpose of reserving power, or in case of forced and emergency shutdowns, the total duration of the subsequent start-up is determined mainly by the duration of the start-up operations of the CCGT steam turbine. A similar problem occurs when the heating CCGT operates in the GTU-TPP mode, when all the steam generated in the waste boilers is discharged into the network water heaters in addition to the steam turbine, which usually stops. The need for this mode arises in situations when the schedule of electrical loads requires unloading power units of the HPC, at the same time, according to the thermal schedule, the thermal load remains at the same level or increases (for example, when passing through the gaps of the schedules of the winter day). The duration of the reverse transition of the CCGT from the GTU-TPP mode to the heating mode is mainly determined by the start-up time of the steam turbine. Not unimportant factor is, in addition to the inevitable loss of heat and fuel at all stages of start-up, the presence of additional losses associated with the discharge of steam from the recovery boiler to the condenser due to the lack of readiness of the steam turbine to receive steam [3].

\section{Research result}

This report summarizes the results of our research on expanding the control range of the CCGT-450 with its participation in load regulation based on the use of bypass steam distribution and reducing the duration of start-up operations in the modes of reserving its power during the night load gap by transferring the CCGT steam turbine to the motor mode when the CCGT operates in the condensation mode or in the heating mode according to the GTU-CHP scheme.

A description of the method for regulating the load of a steam turbine using bypass steam distribution is given in $[1,4]$. It is based on the discharge of a part of the high-pressure steam either into the low-pressure steam supply line, or into the LPC (low pressure cylinder) with a preliminary reduction of the steam pressure and its temperature to the appropriate values. The rest of the high-pressure steam is fed according to the standard scheme to the turbine's HPC. A variety of these methods is their joint application. Summarizing the results of the calculations, it can be stated that at the initial capacity of the CCGT $270 \mathrm{MW}$, the combined use of the above methods for expanding the CCGT's control range using bypass steam distribution allows reducing the lower limit of the control range to the level of $234 \mathrm{MW}$ (52.0\% of the nominal capacity). From the point of view of reliability of combined cycle power plant steam bypass has the following feature - since the power gas turbine and heat load of waste-heat boilers are fixed at the basic level of their magnitude, and reliability remain at the level of "basic" values. At the same time, since the steam turbine, which bears the brunt of variable loads, is more adapted to such work, its indicators of efficiency and reliability, as well as these indicators of the CCGT in general, deteriorate slightly. Although this method allows you to regulate the load of the CCGT within a fairly wide range, at the same time it has a certain disadvantage - the need to modernize the thermal scheme of the steam turbine and does not solve the problem of increasing the manoeuvrability of the CCGT in power reserve modes.

To successfully solve the problem of reducing the duration of start-up operations of the steam turbine and CCGT in general, in the CCGT power reserve modes, when passing load gaps for steam turbines, a non-steam mode is recommended $[5,6]$. Its essence consists in stopping the steam supply to the turbine without disconnecting the generator from the network, which leads to idle rotation of the turbine rotor. In this case, the steam turbine stages do not have a positive heat transfer in the steam flow moving along the flow part, which in this case occurs as a result of steam leakage through the turbine seals. A similar mode is called motor mode when a small amount of cooling steam is added to the flow part to avoid overheating of the metal of the working and guide blades, as a result of the loss of power to the 
condenser for friction and ventilation during idle rotation of the stages. In these modes, the design pressure is maintained, while the entire flow part is under a pressure close to the pressure in the condenser.

The generator thus remains connected to the network, while consuming a small amount of power sufficient to cover mechanical losses in the turbine and mechanical and electrical losses in the generator. For a synchronous turbo generator, this mode is close to the idle mode for generating active power. The mode in which the turbo generator consumes or outputs reactive power by changing the excitation current, in contrast to the motor, is called the synchronous compensator (SC) mode. The use of turbo units in the motor mode as compensating devices for reactive power is possible in cases when there is a deficit or excess of reactive power in the power system [6].

The lack of reactive power is observed in power systems with an extensive network of relatively small length with a voltage of $35,110 \mathrm{kV}$, especially in areas with a large concentration of industrial and agricultural facilities. The stress level is forced to be provided by switching part of the turbine units to the synchronous compensator mode in the absence of other alternative sources of reactive power.

An excess of reactive power in the power system occurs when the most powerful and economical TPP units remain in operation during the minimum load hours, which are forced to work with a leading $\cos \varphi$ value under the conditions of the thermal state of the turbo generators and the stability of parallel operation in the power system. As a rule, such stations are connected to other nodes of the power system via long-distance and high-voltage power lines, which is an additional factor in increasing the voltage level.

Previously conducted experimental studies on condensing and heating steam turbines and accumulated operating experience have shown that the conversion of turbo units to motor mode for periods of night gaps of the electrical load schedule has a number of operational advantages in comparison with the stop-start mode, which significantly increase the manoeuvrability and reliability of the equipment [6].

Thus, when operating a steam turbine in the motor mode (MM), significant $\left(140-200{ }^{\circ} \mathrm{C}\right)$ and sharp (at a speed of $18-20{ }^{0} \mathrm{C} / \mathrm{min}$ ) changes in the steam temperature behind the control stage are excluded, which is due to less cooling of the HPC stages in the zone of the first stages due to the lack of stages of turning, revs, idling, synchronization and switching the generator into the network with a low steam consumption. This significantly accelerates the loading process of the turbine and eliminates low-cycle temperature stresses in the metal. In addition, the above-mentioned possibility of regulating the temperature of the flow part of the turbine by varying the parameters and flow rates of cooling steam creates favourable temperature conditions for the subsequent start of the turbine. Reducing cyclic temperature stresses when using MM increases the durability of steam turbine elements, reduces the probability of vibrations of the last stages of the LPC, and removes restrictions on the number of outputs of the turbine unit in reserve for periods of gaps of daily load schedules $[7,8]$.

When operating a CCGT in condensing mode, MM can be used as a method of reserving the CCGT power during gaps in the power consumption schedule, during emergency and short-term shutdowns (for 8-10 hours) of gas turbines. As shown by the calculated studies of the temperature state of the turbine stages T-150-7 PGU-450 in $\mathrm{MM}$, the scheme proposed in [5] for supplying cooling steam to the turbine during its operation in MM at a pressure in the condenser of 0.004-0.008 $\mathrm{MPa}$ provides a deviation of the metal temperature of the turbine stages by no more than $30-35^{\circ} \mathrm{C}$ relative to the temperature of the nominal mode. One of the features of the operation of the steam turbine in MM is the ability to control its thermal condition by changing the costs and parameters of the cooling steam flows that allows before its start to create the necessary thermal condition steam inlet elements of the steam turbine corresponding to the starting requirements of the user to produce steam from waste heat boilers at start-up CCGT from a stopped state. This means that the load set on the steam turbine can run parallel to the loading of the gas turbines, while the gas turbines can be started in parallel. At low settings and low steam consumption high and low pressure, it can be submitted to the steam turbine with use of a motor scheme mode, and as they increase - according to the standard scheme that eliminates or minimizes the pass steam into the condenser through fast-acting pressurereducing and cooling unit. Taking into account these features, an approximate schedule has been drawn up-the task of starting the CCGT, the duration of the CCGT start-up is about 40 minutes, instead of $80-85 \mathrm{~min}$. when starting the CCGT after stopping for 8-10 hours with the steam turbine stopped. Thus, in the variant of converting a steam turbine to an MM, the duration of starting operations of the steam turbine and, respectively, the CCGT as a whole is reduced by $40-45$ minutes, and the average loading speed of the steam turbine and the CCGT as a whole increases to 5.0 and 15.0 MW per minute, instead of 4.3 and $6.4 \mathrm{MW}$ per minute in the variant of stopping the steam turbine. It is obvious that this reduces the start-up fuel losses and increases the profit of the station due to additional power generation. Calculations carried out to assess the appropriate time to use MM compared to the option of stopping a steam turbine, showed that it varies within 6-10 hours, depending on the cost of fuel and the tariff for electricity in the wholesale electricity market [2].

When working with the CCGT-450, which has 2 peak network heaters in the thermal scheme, the steam turbine manufacturer has provided for the GTU-TPP mode in the heating mode, when all the steam generated in the waste water boilers is discharged into the network water heaters in addition to the steam turbine, which, in accordance with the manufacturer's instructions, stops. The operational disadvantage of this mode is the need to stop the steam turbine with subsequent start-up, which is associated with fuel losses during start-up, delayed loading of the steam turbine and the CCGT as a whole, and a decrease in its resource characteristics. 
As an alternative, when switching the CCGT to the GTU-TPP mode, instead of stopping the steam turbine, it is proposed to switch it to the MM, while the operation of the steam turbine has its own characteristics:

- as gas turbines and waste heat boilers remain in operation, the steam for cooling the flowing part of the steam turbine is taken from the respective steam pipes of the steam (other than steam turbines) on a network heaters, including: front sealing of HPC - from a steam pipe high pressure steam via pressure-reducing and cooling unit; for steam inlet CHP - from the highpressure steam line through the bypass mode line main steam gate valve; for LPC is from the line supplying steam to the high pressure on network water heater 1 (NWH-1), while, if necessary, is cooled in the mixer of steam condensate from the condenser;

- since the operating conditions of the flow part of the steam turbine and the condensing unit do not differ from their operation when converting the steam turbine to $\mathrm{MM}$ in the condensing mode of the CCGT, the pressure in the condenser can be maintained at the level of 0.004-0.006 MPa.

Technology transfer of CCGT to GTU-TPP mode with steam turbine transferring in $\mathrm{MM}$ the following: 1) CCGT is unloaded in accordance with the operational manual "base" electrical load in which constraints occur in gas turbines - 90-95 MWt (below this power of the gas turbine to unload impractical); 2) at heat setting corresponding steam pressure in the extraction steam turbine at NWH-1 and NWH-1 in accordance with a thermal schedule of heat supply at the "base" load of the

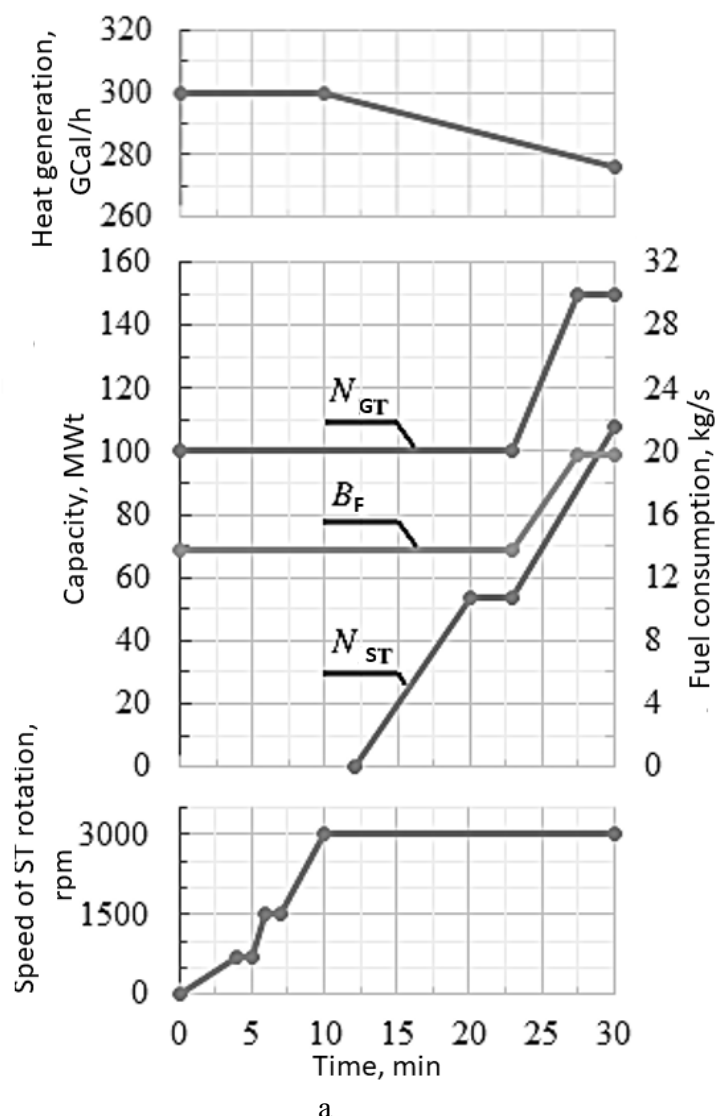

CCGT with the required amount of heat; 3) the NWH is gradually switched over to steam in accordance with the manufacturer's instructions when the CCGT is switched to the GTU-TPP mode; 4) after the steam turbine is switched to the GTU-TPP mode, the steam turbine is transferred to the $\mathrm{MM}$ according to the technology described above. As with the CCGT operation in the GTU-TPP mode, the decrease in the CCGT's electrical power is compensated by an increase in heat output, while the CCGT's adjustment range is expanded by $20.6 \%$ to $56.2 \%$. This means that in the market of electricity and capacity, the CCGT can compete with gas-fuel-oil condensing power units in the regulation range.

For Fig. 1 graphs of steam turbine start-up and CCGT loading from the GTU-TPP mode for options for stopping the steam turbine and converting it to $\mathrm{MM}$ are given. The peculiarity of the first option is that the duration of starting a steam turbine after stopping for 610 hours with working gas turbines and waste boilers is at least 30 minutes. After a set rpm, synchronization, and enable the generator to the network loading of the steam turbine capacity of 55-60 MW produced in accordance with the start-up of CCGT with a parallel start of gas turbines, after which the gas turbines and steam turbines in parallel, loaded to the maximum load for a given thermal load of the steam turbine (Fig 1a). The duration of starting operations of the steam turbine and loading the CCGT to the rated power, as can be seen from Fig. $1 \mathrm{a}$, is 30.5 minutes.

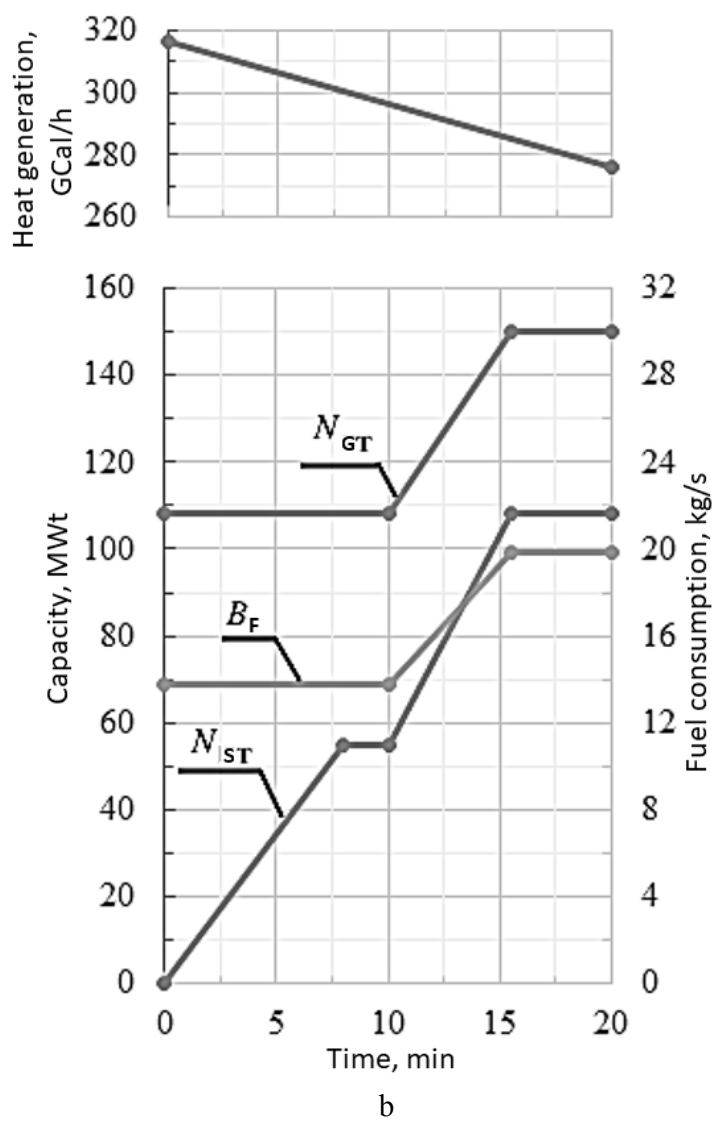

Fig. 1. Simplified graphs: $a$ - steam turbine start-up and CCGT loading in GTU-TPP mode with PT stop; $b$ - CCGT loading in GTUTPP mode with PT transferring to MM. 
The peculiarity of starting a steam turbine at the exit from the MM is that the thermal state of the flow part of the turbine is such that high and low pressure steam is allowed to flow into the turbine, which accelerates the loading process of the steam turbine and the CCGT as a whole (Fig. 1b). The total duration of the CCGT output to the calculated load for electricity and heat in this variant is estimated at 15.5 minutes, thus, the duration of startup operations is reduced by 14.5 minutes, respectively, the start-up fuel losses are reduced, and the profit of the station increases due to additional power generation. Calculations carried out for various combinations of the cost of conventional fuel and electricity on the market, the tariff for heat showed that the duration of the appropriate time for converting a steam turbine to an MM when operating a PGU-450T in the GTU-TPP mode ranges from 10 to 18.0 hours.

The disadvantage of the proposed solution is that the use of such a mode on the PGU-450T in the absence of peak network heaters will require additional installation of the corresponding parameters and performance of the pressure-reducing and cooling unit.

\section{Conclusion}

1. At the initial capacity of the PGU-450 $270 \mathrm{MW}$, the use of the method of bypass steam distribution of the steam turbine ensures reliable operation of gas turbines and recovery boilers and allows reducing the lower limit of the CCGT adjustment range to the level of $234 \mathrm{MW}$ ( $52.0 \%$ of the nominal capacity).

2. When reserving the power of the PGU-450 in the condensing mode, switching the steam turbine to the motor mode reduces the duration of starting operations of the steam turbine and, accordingly, the CCGT as a whole by $40-45 \mathrm{~min}$., increases the average loading speed of the steam turbine and the CCGT as a whole to 5.0 and 15.0 MW per min. instead of 4.3 and 6.4 MW per minute in the variant of stopping the steam turbine.

3. Transferring of a steam turbine in the motor mode operation of PGU-450 mode of the gas turbine increases the manoeuvrability of the CCGT as a whole by reducing the time of starting of steam turbine and loading the GTU to its rated load when the GTU with a GTU-HPP in the nominal mode at $14.5 \mathrm{~min}$.

4. The transferring of the steam turbine in the motor mode increases the reliability of its operation start-up with low steam consumption due to removing the cyclical changes in temperature steam inlet of the turbine and vibration fluctuations in the last stages in LPC.

The research was supported by the RFBR (grant no. 18-0801090).

\section{References}

1. E.K. Arakelyan, A.V. Andryushin, S.Yu. Burtsev, K.A. Andryushin, Ways to expand the regulation range of steam-gas installations (CCGT) and their comparative efficiency in terms of efficiency, manoeuvrability and reliability (for example, PGU450). Review article // Vestnik MPEI., 6 (2017), pp. 20-30.

2. E.K. Arakelyan, A.V. Andryushin, S.Yu. Burtsev, K.A. Andryushin. Technical and economic feasibility of converting a steam turbine PGU-450 to a motor mode//Electric stations, 6 (2017), pp. 25-29.

3. E.K. Arakelyan, A.V. Andryushin, S. Yu. Burtsev, K. A. Andryushin. Study of the technical and economic feasibility of converting the T-125/150 steam turbine to the motor mode when operating the PGU-450 in the GTU-TPP mode//Thermal Engineering, 12 (2018), pp. 53-65.

4. E.K. Arakelyan, A.V. Andryushin, S.Yu. Burtsev, K.A. Andryushin. Technical and economic feasibility of developing innovative technological solutions to expand the regulation range of highcapacity CCGT//Materials of the international conference "Modern problems of Thermophysics and energy" SPTE-2017, Moscow, NRU "MPEI". v. 1.

5. E.K. Arakelyan, I.O. Bezdelgin, K.A. Andryushin. Temperature State of the Flow-Through Part of a T125/150 PGU-450 Steam Turbine Operating in the Steam-Free and Motor Regimes//Power Technology and Engineering, v.49, №4, (2015), pp.291-295.

6. E.K. Arakelyan. Improving the efficiency and manoeuvrability of equipment for thermal power stations/E. K. Arakelyan, V.A. Starshinov. Moscow: publishing house of MPEI (1993).

7. V.A. Grachev, V.V. Kulichikhin, V.V. Ludomirsky. Thermal state of the T-100-130 turbine in motor mode//Power plant, 9 (1976), pp. 19-22.

8. A.D. Trukhny, L.N. Kobzarenko, A.A. Madoyan, E.K. Arakelyan, A. A Kochetov, V.V. Paschenko. Low-cycle reliability of K-200-130 turbine rotors at various methods of their output to the night reserve // Thermal Engineering, 10 (1982), pp. 50-57. 